\title{
Solid state synthesis and its characterization of high density cordierite ceramics using fine oxide powders
}

\author{
Toshio OGIWARA, ${ }^{\dagger}$ Yoshimasa NODA, ${ }^{*}$ Kazuo SHOJI ${ }^{* *}$ and Osamu KIMURA*
}

Department of General Education, Ashikaga Institute of Technology, 268-1, Omae, Ashikaga, Tochigi, 326-8558

*Collaborative Research Center, Ashikaga Institute of Technology, 268-1, Omae, Ashikaga, Tochigi, $326-8558$

${ }^{* *}$ Department of Electrical and Electronic Engineering, Ashikaga Institute of Technology, 268-1, Omae, Ashikaga, Tochigi, $326-8558$

First, we succeeded in synthesizing and sintering cordierite ceramics via the solid state reaction route without the melting process by using single phase oxide powders. They are highly pure and fine amorphous silica, $\alpha$-alumina and magnesia powders. Usually, cordierite ceramics was synthesized by a sol-gel route. Alternatively, it was prepared by a solid state reaction route using impure minerals such as talc, or the other which required melt-quenching and crystallization processes, though using single phase raw material powders. This is probably because single phase raw material powders especially alumina are deficient in reactivity. We have succeeded in synthesizing cordierite ceramics via the solid state reaction route without meltquenching and crystallization processes, by adopting a reactive $\alpha$-alumina as one of raw material powders. As a result, cordierite formation of the starting raw material mixture went to completion at $1270^{\circ} \mathrm{C}$. The mixture was sintered at $14300^{\circ} \mathrm{C}$ for $2 \mathrm{~h}$. Its bulk density reached $98 \%$ theoretical, its flexural strength reached $243 \mathrm{MPa}$, which agreed with the best value already reported, its fracture toughness was $3.5 \mathrm{MPa} \cdot \mathrm{m}^{1 / 2}$ far larger than the reported value of $2.3 \mathrm{MPa} \cdot \mathrm{m}^{1 / 2}$, its thermal expansion coefficient (from RT. to $800^{\circ} \mathrm{C}$ ) is $1.8 \times 10^{-6} / \mathrm{K}$, which might be probably the ultimately smallest value experimentally expected and its dielectric constant was sufficiently small as 4.8 to 5.2 between extremely a wide frequency range, namely, from $1 \mathrm{MHz}$ to $1 \mathrm{GHz}$ with low loss tangent of $<6 \times 10^{-3}$. These properties were found more excellent or at least comparable compared with the best properties reported already and suitable for substrate materials on micro-electronic applications.

(๑2010 The Ceramic Society of Japan. All rights reserved.

Key-words : Synthesis, Cordierite, High purity oxide, Solid state reaction route, Physical properties, High density

[Received December 2, 2009; Accepted January 15, 2010]

\section{Introduction}

The phase diagram of cordierite was first reported by Rankin and Merwin on the ternary system $\mathrm{MgO}-\mathrm{Al}_{2} \mathrm{O}_{3}-\mathrm{SiO}_{2}{ }^{1)}$ Cordierite ceramics is one of the candidates as a substrate material for microcircuit applications in electronic fields due to its low thermal expansion coefficient and low dielectric constant. Also, it has been utilized as a ceramic honeycomb for a catalystic support in an automobile exhaust system. However, it is difficult to obtain dense cordierite ceramics by the sintering process because its sintering temperature range is limited within $25^{\circ} \mathrm{C}$ below its melting point of $1455^{\circ} \mathrm{C} .{ }^{2)}$ Many previous studies were reported about the sinterability of cordierite ceramics. Recently, dense cordierite ceramics have been produced at low temperature by the sol-gel method using alkoxides of $\mathrm{Si}$ and $\mathrm{Al} .{ }^{3)}$ However, the starting materials via this method are very expensive and the fabrication processes are complicated. In addition, the properties of the obtained ceramics were not excellent compared with those reported already. ${ }^{4), 5)}$

Alternatively, cordierite ceramics were prepared by a solid state reaction route using impure minerals such as talc, ${ }^{6)}$ or the other which required melt-quenching and crystallization processes, though using single phase raw material powders. ${ }^{7)}$ The properties of both sintered ceramics were also insufficient compared with those reported already. ${ }^{4), 5)}$

This paper aims to synthesize cordierite ceramics by the conventional solid state reaction without melt-quenching and crys-

Corresponding author: T. Ogiwara; E-mail: togi@ ashitech.ac.jp tallization processes using highly pure, fine and reactive oxide powders. In addition, it aims to obtain highly densified cordierite ceramics with enhanced properties.

\section{Experimental}

The starting raw oxide powders were used high purity Magnesia (Soekawa Chemical Co., Ltd., 99.99\%), $\alpha$-alumina with an average diameter of $0.1 \mu \mathrm{m}$ (TM-DAR, Taimei Chemicals Co., Ltd., 99.99\%), and amorphous Silica (Kanto Chemical Co., Inc., 99.9\%). Magnesia powder was heated at $900^{\circ} \mathrm{C}$ for $2 \mathrm{~h}$ to remove magnesium carbonate. These raw material powders are expected to react with each other at low temperatures. Especially, TMDAR is prepared by thermally decomposition of aluminum dawsonite $\left\{\mathrm{NH}_{4} \mathrm{AlCO}_{3}(\mathrm{OH})_{2}\right\}$ so that it is highly reactive compared with the other commercially available $\alpha$-alumina. The starting mixture with a stoichiometric composition of cordierite $\left(\mathrm{MgO}: \mathrm{Al}_{2} \mathrm{O}_{3}: \mathrm{SiO}_{2}\right.$ molar ratio $\left.=2: 2: 5\right)$ was prepared from these oxide powders. The powders were mixed in a planetary ball mill (Itoh Industry Co., Ltd.) using zirconia balls of $3 \mathrm{~mm}$ in diameter in isopropyl alcohol (IPA) for $3 \mathrm{~h}$, added with $1 \%$ of poly vinyl butyral (PVB). After drying, the mixture was pressed in a die at a pressure of $30 \mathrm{MPa}$, CIPed at a pressure of $200 \mathrm{MPa}$, and heattreated in air for $2 \mathrm{~h}$ from $1100^{\circ} \mathrm{C}$ to $1350^{\circ} \mathrm{C}$ to examine reaction procedure of the compact of the mixture and determine proper calcining temperature of the mixture for its sintering. The scanning electron microscope (SEM) observations for the powders and the cross section of the sintered samples were carried out using an SEM instrument (JSM-5200, JEOL Ltd.). Crystalline phases in the heat-treated samples were identified by XRD 
(RINT 2000, Rigaku Co.) using $\mathrm{Cu} \mathrm{K} \alpha$ radiation. Bulk density of the sample was determined by the liquid displacement method using water, namely Archimedean method. Flexural strength of the sample was evaluated by the three point bending experiment and Young's modulus was estimated from the stress-strain curve during the experiment. The values of Vichers hardness and fracture toughness were obtained from the indentation process and IF method. ${ }^{8)}$ Differential scanning calorimetry (DSC) of the green compact was performed employing a Rigaku DSC 8270 equipment at a heating rate of $5 \mathrm{~K} / \mathrm{min}$ and thermal expansion coefficient of the sample was measured using a dilatometer (TMA 8310, Rigaku Co.). Dielectric constants were estimated from the values of the capacitance measured at $1 \mathrm{MHz}$ and $1 \mathrm{GHz}$ using impedance analyzers (YHP4192A and 4191A, YokokawaHewlett-Packard Co.), respectively.

\section{Results and discussion}

Figure 1 shows representative DSC plots of the compact of

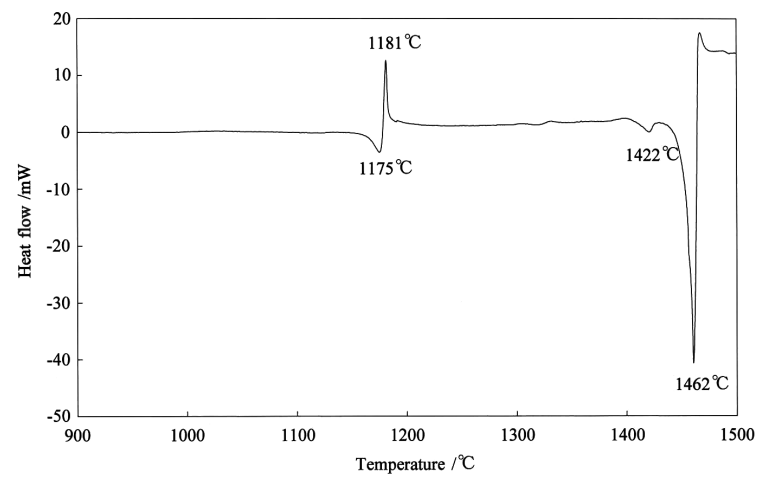

Fig. 1. Representative DSC plot for the compact of the starting mixture.

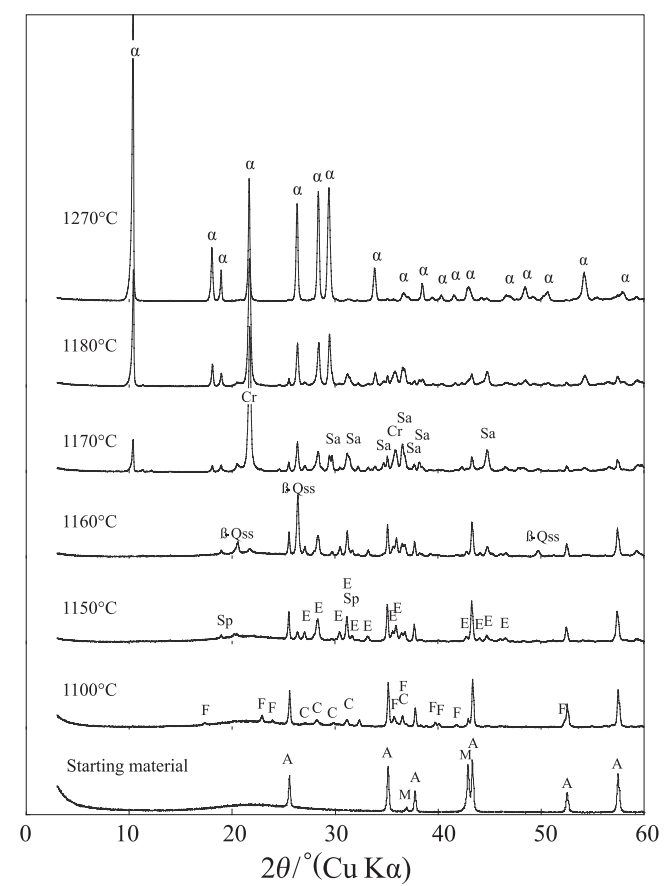

Fig. 2. XRD patterns for the compact of the starting mixture heattreated at various temperatures for $2 \mathrm{~h}$. A: Corundum, M: $\mathrm{MgO}$, F: Forsterite, C: Clinoenstatite, Sp: Spinel, E: Enstatite, $\beta$-Qss: $\beta$-Quartz solid solution, Cr: Cristobalite, Sa: Sapphirine, a: $\alpha$-Cordierite. the mixture. As seen, a sharp exothermic peak at $1181^{\circ} \mathrm{C}$ and three endothermic peaks at $1175^{\circ} \mathrm{C}, 1422^{\circ} \mathrm{C}$ and $1462^{\circ} \mathrm{C}$ are observed. The sharp exothermic peak at $1181^{\circ} \mathrm{C}$ can be assigned to crystallization of cordierite from $\beta$-quartz solid solution $(\beta$ Qss), cristobalite and sapphirine on the basis of XRD patterns shown in Fig. 2. The first endothermic peak at $1175^{\circ} \mathrm{C}$ that begins at $1160^{\circ} \mathrm{C}$ corresponds to formation of $\beta$-Qss with cristobalite and disappearance of a broad diffraction peak at around $2 \theta=21.8^{\circ}$, which corresponds to amorphous silica shown in Fig. 2. The second peak at $1422^{\circ} \mathrm{C}$ corresponds probably to libration of silanol radicals from silica. The last peak at $1462^{\circ} \mathrm{C}$ is assigned to the melting of cordierite.

Figure 2 shows XRD patterns of the compact of the mixture heat-treated at $1100-1270^{\circ} \mathrm{C}$ for $2 \mathrm{~h}$. In the pattern for the compact of the mixture heat-treated at $1100^{\circ} \mathrm{C}$, peaks of forsterite, clinoenstatite, corundum and weak peak of magnesia, a broad diffraction peak of amorphous silica at around $2 \theta=21.8^{\circ}$ are observed. This result indicates that all magnesia reacts with a part of amorphous silica to form forsterite and clinoenstatite below $1100^{\circ} \mathrm{C}$. At this temperature, corundum remains unreacted. At the narrow temperature range from $1150^{\circ} \mathrm{C}$ to $1180^{\circ} \mathrm{C}$, a considerable change in XRD patterns is observed. The weak peaks of spinel and enstatite appear and the peaks of forsterite

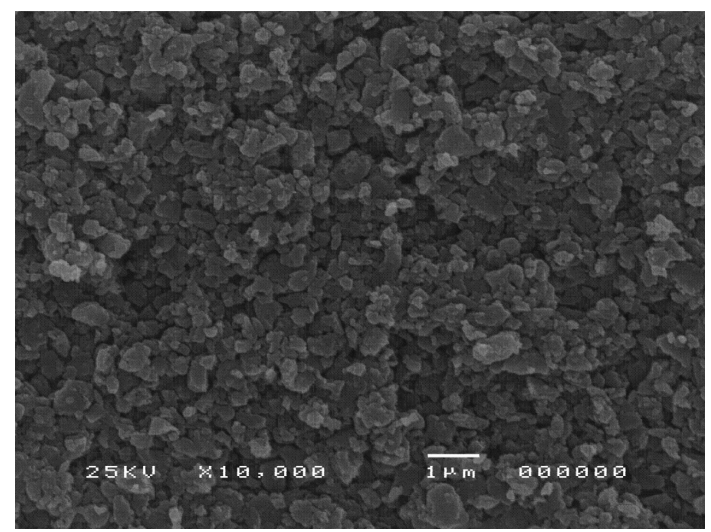

Fig. 3. SEM photograph of the pulverized powder.

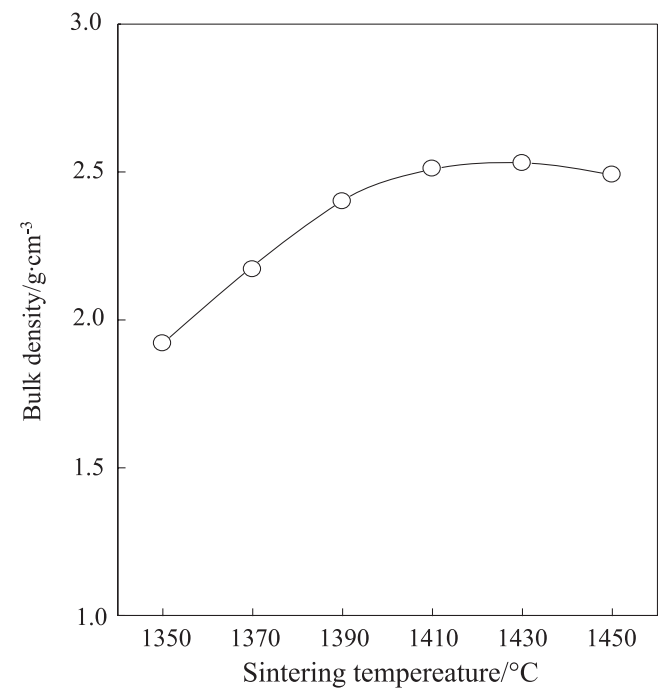

Fig. 4. Bulk density of the sample sintered as a function of sintering temperature. 

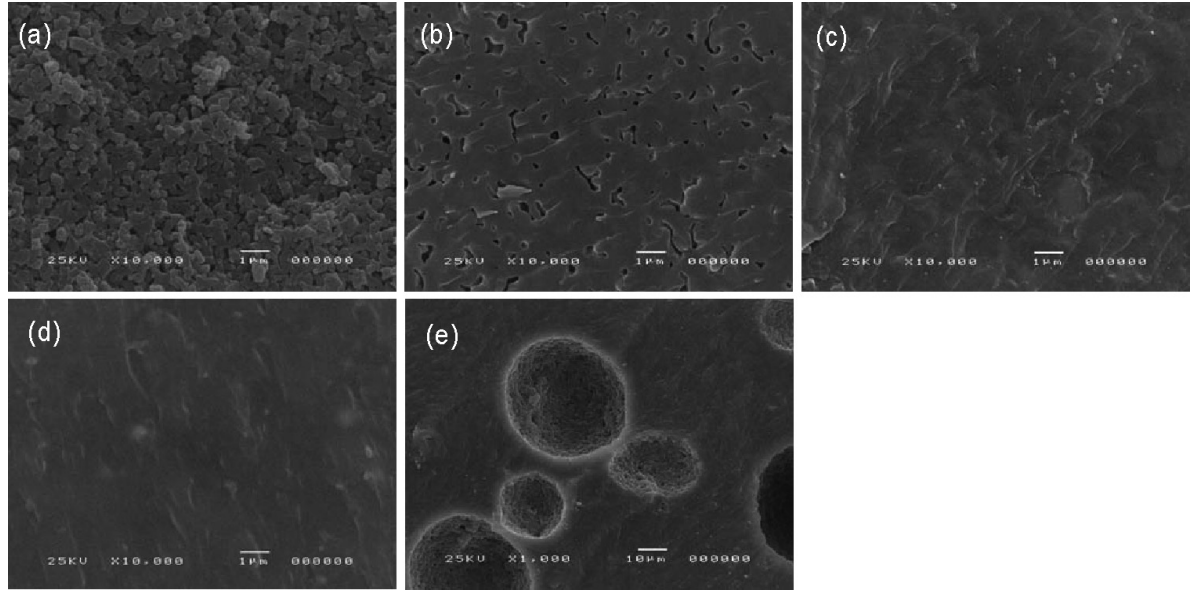

Fig. 5. SEM photographs of the cross sections for the samples sintered at various temperatures. (a) $1300^{\circ} \mathrm{C}$, (b) $1350^{\circ} \mathrm{C}$, (c) $1400^{\circ} \mathrm{C}$, (d) $1430^{\circ} \mathrm{C}$ and (e) $1450^{\circ} \mathrm{C}$

and clinoenstatite vanish at $1150^{\circ} \mathrm{C}$. At $1160^{\circ} \mathrm{C}$, the peak of $\beta$ quartz solid solution appears accompanied by the disappearance of a broad diffraction peak of amorphous silica. Cristobalite, sapphirine and cordierite appear at $1170^{\circ} \mathrm{C}$ with decrease in the peak intensity of the $\beta$-quartz solid solution. At $1240^{\circ} \mathrm{C}$, the main crystal phase is $\alpha$-cordierite with a weak diffraction peak of spinel. Finally, only $\alpha$-cordierite phase is observed for the compact of the mixture heat-treated above $1270^{\circ} \mathrm{C}$. Accordingly, the proper calcination temperature of the raw material mixture was determined as $1240^{\circ} \mathrm{C}$. It was the lowest temperature at which sintering process of the mixture was expected to proceed easily.

First, the mixture was calcined at $1240^{\circ} \mathrm{C}$ for $2 \mathrm{~h}$ and then pulverized in a planetary ball mill using zirconia balls of $3 \mathrm{~mm}$ in diameter in IPA for $6 \mathrm{~h}$. Next, it was pulverized again for $48 \mathrm{~h}$ in a usual ball mill also using zirconia balls of $3 \mathrm{~mm}$ in diameter in IPA containing a surfactant (Kusumoto Chemicals) and dried. The pulverized powder was added with $1 \%$ of PVB, pressed in a die at a pressure of $30 \mathrm{MPa}$, CIPed at a pressure of $200 \mathrm{MPa}$ to form its compact. The compact was sintered in air from $1350^{\circ} \mathrm{C}$ to $1450^{\circ} \mathrm{C}$ for $2 \mathrm{~h}$, respectively. As seen, from the SEM photograph in Fig. 3, the grain size of the pulverized powder is about $0.5 \mu \mathrm{m}$, indicating that sufficiently fine pulverization was attained. Figure 4 shows bulk density of the sintered sample as a function of sintering temperature. It increases with increasing sintering temperature, reaches a maximum of $2.53 \mathrm{~g} / \mathrm{cm}^{3}$ at $1430^{\circ} \mathrm{C}$ and decreases to $2.49 \mathrm{~g} / \mathrm{cm}^{3}$ at $1450^{\circ} \mathrm{C}$. The true density of the sample sintered at $1430^{\circ} \mathrm{C}$ was determined as $2.59 \mathrm{~g} / \mathrm{cm}^{3}$ by the conventional pycnometer method. Accordingly, a sufficiently high densification of $98 \%$ was attained at $1430^{\circ} \mathrm{C}$ sintering. Figure 5(a) to (e) show SEM photographs of the cross sections for the samples sintered at various temperatures. As visually observed, the sample density increases with increasing temperature and almost complete densification is attained at $1430^{\circ} \mathrm{C}$ sintering. However, many porous regions are observed in the matrix for the sample sintered at $1450^{\circ} \mathrm{C}$ probably due to the libration of silanol radicals contained in amorphous silica. This phenomenon corresponds to the decrease in bulk density and the endothermic peak observed at $1422^{\circ} \mathrm{C}$ in Fig. 1.

In addition, Fig. 6 shows flexural strength of the sintered sample as a function of sintering temperature. It increases with increasing sintering temperature, reaches a maximum of 243 $\mathrm{MPa}$ at $1430^{\circ} \mathrm{C}$ and decreases to $200 \mathrm{MPa}$ at $1450^{\circ} \mathrm{C}$. This behavior agrees with exactly that of the bulk density, described

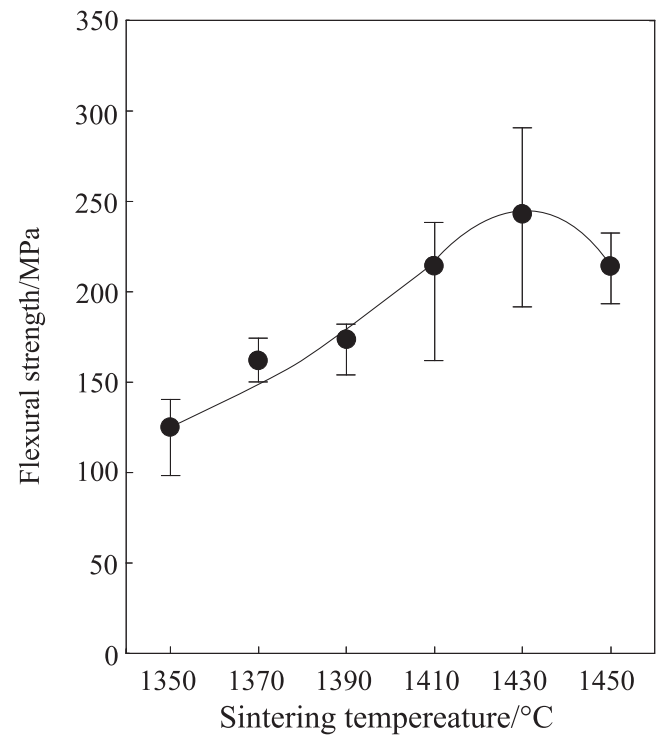

Fig. 6. Flexural strength of the sintered sample as a function of sintering temperature.

above.

Table 1 summarizes the values of thermo-mechanical and electrical properties of our sample sintered at $1430^{\circ} \mathrm{C}$ with the standard values previously reported, ${ }^{4), 5)}$ respectively. As seen in the Table, all the values of the properties for the sintered sample are comparable or at least prominent compared with the values of the standard sample. It is noted that the latter values are the best values collected from various sources. First, the value of Vichers hardness is a little smaller than the standard value. Next, the value of flexural strength agrees with the standard value. The value of Young's modulus enhanced twice the standard value. The value of fracture toughness is $3.5 \mathrm{MPa} \cdot \mathrm{m}^{1 / 2}$ far larger than the standard value and comparable that of alumina $=4.0 \mathrm{MPa} \cdot \mathrm{m}^{1 / 2}$. The coefficient of thermal expansion is a little larger than the standard value, which was theoretically evaluated by Evans et $\mathrm{al}^{4), 9)}$ from temperature dependence of the lattice constants of cordierite. Therefore, this value may be probably the ultimate one practically obtained. The value of dielectric constant 4.8 (at $1 \mathrm{MHz}$ ) -5.2 (at $1 \mathrm{GHz}$ ) is almost the same as the standard value 
Table 1. Thermo-mechanical and Electrical Properties of Sintered Samples

\begin{tabular}{l|c|c}
\hline \multicolumn{1}{c|}{ Properties } & Our sample & Standard $^{4), 5}$ \\
\hline Sintering temperature $\left({ }^{\circ} \mathrm{C}\right)$ & 1430 & \\
Bulk density $\left(\mathrm{g} / \mathrm{cm}^{3}\right)$ & 2.53 & \\
Vickers hardness $(\mathrm{GPa})$ & 7.5 & 8.2 \\
Flexural strength $(\mathrm{MPa})$ & 243 & 245 \\
Young's modulus $(\mathrm{GPa})$ & 281 & 139 \\
Fracture toughness $\left(\mathrm{MPa} \cdot \mathrm{m}^{1 / 2}\right)$ & 3.5 & 2.3 \\
\hline Coefficient of thermal expansion & 1.8 & $1.5^{9)}$ \\
$\left(\times 10^{-6} / \mathrm{K}\right)\left(\mathrm{RT} .-800^{\circ} \mathrm{C}\right)$ & 4.8 & 5.0 \\
\hline Dielectric constant $(1 \mathrm{MHz})$ & 5.2 & \\
$\quad(1 \mathrm{GHz})$ & 1.2 & \\
Loss tangent $\left(1 \mathrm{MHz}, \times 10^{-3}\right)$ & 6.3 & \\
\hline \multicolumn{1}{c|}{$\left(1 \mathrm{GHz}, \times 10^{-3}\right)$} & & \\
\hline
\end{tabular}

True density of our sample $=2.59 \mathrm{~g} / \mathrm{cm}^{3}$.

of 5.0 with low loss tangent of $<6 \times 10^{-3}$ even at $1 \mathrm{GHz}$. It should be noticed that the value remains constant independent of the frequency over extremely wide frequency range. On the other hand, dielectric constant of the sample prepared by a sol-gel route ${ }^{10)}$ decreases with increasing frequency even at $\mathrm{MHz}$ region probably due to imperfectness in the sample, though the value at 1 $\mathrm{MHz}$ is almost the same. Furthermore, it is considerably low that of alumina $=9.5 .^{4), 5)}$ These experimental results indicate that the sample can be applicable as a substrate material for microelectronic devices.

\section{Conclusion}

Synthesis of cordierite ceramics was attained using high purity and fine oxide powders by solid state reaction and fabrication of high dense cordierite ceramics was also attained. Cordierite formation for the starting raw material mixture went to completion at $1270^{\circ} \mathrm{C}$. The density of the sample sintered at $1430^{\circ} \mathrm{C}$ reached $98 \%$ of the true density. In addition, its flexural strength was enhanced to $240 \mathrm{MPa}$, which is almost the same as that of standard value. Coefficient of thermal expansion $\left(1.8 \times 10^{-6} / \mathrm{K}\right)$ and dielectric constant $(4.8$ at $1 \mathrm{MHz})$ are also almost the same as that of standard value. In addition, dielectric constant remains constant independent of the frequency over extremely wide frequency range from $1 \mathrm{MHz}$ to $1 \mathrm{GHz}$ with loss tangent of $<6 \times$ $10^{-3}$. As a conclusion, high density and outstanding characteristics cordierite ceramics was obtained by using simple powder mixing method without using complex sol-gel method.

\section{References}

1) G. A. Rankin and H. E. Merwin, Am. J. Sci., $4^{\text {th }}$ Series, 45, 301-325 (1918).

2) M. G. M. U. Ismail, H. Tsunatori and Z. Nakai, J. Am. Ceram. Soc., 73[3], 537-543 (1990).

3) H. Suzuki, K. Ota and H. Saito, Yogyo Kyokai Shi, 95[2], 3237 (1987).

4) B. H. Mussler and M. W. Shafer, Ceram. Bull., 63, 705-714 (1984).

5) Editional Committee of Cyclopedia of Fine Ceramics, "Cyclopedia of Fine Ceramics," Published by Gihodou (1987) p. 185 [in Japanese].

6) J. M. Filio, K. Sugihara, K. Kasai and F. Saito, J. Chem. Eng. Japan, 26[5], 565-569 (1993).

7) S. H. Knickerbocker, A. H. Kumar and L. W. Herron, Am. Ceram. Soc. Bull., 72[1], 90-95 (1993).

8) K. Niihara, R. Morena and D. P. H. Hasselman, J. Mater. Sci. Lett., 1, 13-16 (1982).

9) D. L. Evans, G. R. Fischer, J. E. Geiger and F. W. Martin, J. Am. Ceram. Soc., 63[11-12], 629-634 (1980).

10) I. Jankovic-Castvan, I. Lazarevic, B. Jordovic, R. Petrovic, D. Tanaskovic and D. Janackovic, J. Eur. Ceram. Soc., 27, 36593661 (2007). 